\title{
CRYPTOSPORIDIOSIS PROVOKING DIARRHEA AMONG INFANTS, TODDLERS AND PRESCHOOL CHILDREN
}

\section{By}

MARWA A. GEIETH'1, ESSAD M. MONAZEEE ${ }^{2}$, MOHAMED A. ELMARAGHY ${ }^{3}$, AHMED H. ABDEL MOTAMED ${ }^{4}$ AND HALA M. EL-ASKARY ${ }^{1}$

Departments of Medical Parasitology ${ }^{1}$ and Pediatrics ${ }^{3}$, Faculty of Medicine, Beni-Suef University, Department of Pediatrics ${ }^{2}$, Faculty of Medicine, Al Azhar University, Cairo, and Department of Pediatrics ${ }^{4}$, Beni-Suef General Hospital, Beni-Suef University,

Egypt ( ${ }^{*}$ Correspondence: marwaghieth@yahoo.com)

\section{Abstract}

Cryptosporidium intestinal coccidian is a preeminent account for infectious diarrhea with reference to children. Oocyst may escape ordinary microscopic analysis or immune detection; molecular techniques are of convenient use. This study intent to detect cryptosporidiosis infection among children, and debates risks for infection. A total of 189 children with age range from under one to five complaining of gastrointestinal manifestations were examined coproscopically, by acid fast stain, ELISA and nested PCR (nPCR) for Cryptosporidium from June to September. Infection was proved by nPCR among $13(6.8 \%)$ samples. ELISA sensitivity merit stool staining $(77 \%, 53.8 \%$, respectively), however all positive samples by microscopy were settled by $\mathrm{nPCR}$. Age groups $(\mathrm{P}=0.02)$ were statistically associated with infection. Source of water $(\mathrm{OR}=0.069,95 \% \mathrm{CI}=0.004 / 1.165, \mathrm{P}=0.01)$ and presence of undigested food particles on microscopy $(\mathrm{OR}=1.058,95 \% \mathrm{CI}=0.521 / 6.154, \mathrm{P}=0.02)$ were risks for infections. No other variables were predicated risks. Infection was potent among preschool children $(46.2 \%)$, toddlers $(38.5 \%)$ and then infants $(15.4 \%)$. Cryptosporidiosis should be doubtful among children with diarrhea during preschool age. Source of water for ordinary drinking activities or for infants with non-exclusive breast or complementary feeding should be considered as hazards aspects for acquiring Cryptosporidium.

Key words: Cryptosporidiosis, Children, Diarrhea, ELISA, Stain, nPCR

\section{Introduction}

Cryptosporidium is distributed universally among all ages; however it is an imperative infectious disease common in children (Fathy et al, 2014). The two species parvum and hominis are incorporated to motif of human infections (Bouzid et al, 2013).

It is linked to wide range of clinical manifestations depending on the nutrition, immunity state, and age of patients; however diarrhea is a common characteristic of the disease (Mor and Tzipori. 2008; Bouzid et al, 2013).

Infection is a common pediatric barrier; during the early two years it is linked to increase mortality (Bouzid et al, 2018). In addition to variety of childhood impediments; dehydration, under nutrition, weight loss, malabsorption, affecting growth of children by expanded diarrhea (Nath et al, 2015; Khalil et al, 2018).

The story of malnutrition and cryptospo- ridiosis is a vicious circle, under nutrition aggravates infection and decrease immunity. On the other hand, cryptosporidiosis affects nutrients absorption causing malnutrition and lengthens the disease duration enforcing reinfections (White et al, 2015). Using molecular techniques for confirmation of infection is helpful (Helmy et al, 2014; Ghieth et al, 2018).

At Beni-Suef community a high frequency of infection was reported in older age groups (Abdel Gawad et al, 2018), thus making a spotlight on the symptomatic under-five children was pivotal for better management of cryptosporidiosis induced manifestation.

\section{Subjects and Methods}

Ethical circumstances and study population: This cross-sectional study including 189 children with age up to 5 attending the Beni-Suef Pediatrics Outpatients Clinic and complaining of gastro-intestinal com- 
plains. A constructed questionnaire was fulfilled by parents of children. All parents were previously notified about the research aim; they found no trouble to ignore the study. Samples collection was done only by their approval.

All children were asked to collect from one to three stool samples. It was divided into three parts, first one for doing microscopy by direct wet mount and concentration technique after adding saline and Lugol's iodine to detect the intestinal protozoans (oo)cysts, ova and any stages of helminthes using x10 \& x40 objectives. For microscopic diagnosis of cryptosporidiosis oocysts, the Modified Ziehl Neelsen (MZN) stain was prepared and samples were examined. The remaining two parts were immediately stored at $-20^{\circ} \mathrm{C}$ for further assays.

Copro-immuno-detection of cryptosporidiosis: A complete set of the stored samples was subjected to Cryptosporidium coproantigen detection by using ELISA Kits (RIDASCREEN Cryptosporidium-C1201R-Biopharm AG, Germany) by the specific antibodies to $C$. parvum and C. hominis detection. Processing was done according to the manufacturer`s instructions.

Copro-PCR assay: nPCR technique was used for molecular diagnosis of cryptosporidiosis using Cryptosporidium oocyst wall protein (Spano et al, 1997). The last set of the stored samples was subjected to DNA extraction using Favor Prep DNA isolation Kit (Favorgen Biotech, Taiwan, Cat. No. FASTI001-1). Processing of samples was done according to the manufacturer`s instructions.

PCR amplification: Performing of samples was done using two sets of primers; BCOWP forward and reverse (PedrazaDíaz et al, 2000), mixture and conditions of reaction were done. PCR amplified products were run on agarose gel electrophoresis $(1.5 \%)$ then visualized by the UV Transilluminator after adding the ethidium bromide stain.
Statistical analysis: By using the statistical package SPSS version 17 (Chicago, IL, USA). Considering nPCR as a gold reference standard, sensitivity, specificity, PPV and NPV were estimated and the kappa agreement was performed to prove validity of acid fast stained microscopy and ELISA regarding $\mathrm{nPCR}$ results in diagnosis of Cryptosporidium infection. Percentage and frequency were used to describe qualitative variables while $\mathrm{M} \pm \mathrm{SD}$ was designed for quantitative variables. Risk factors for acquiring infection diagnosed by nPCR were done using univariable logistic regression analysis. The odds ratio (OR), 95\% confidence interval $(\mathrm{CI})$ and $P$ value $(\leq 0.05)$ were estimated.

\section{Results}

Diagnostic validity: Out of 189 children, Cryptosporidium infection was proved molecularly in 13 samples (6.8\%), by ELISA in $7.9 \%$ of samples and by stained microscopy in $3.7 \%$. Microscopy versus ELISA gave maximum specificity and PPV $(100 \%$ for each) than ELISA, which gave higher sensitivity (77\%) than stool (53.8\%). Both microscopy and ELISA gave a substantial Kappa agreement $(0.61,0.62$, respectively) as diagnostic tools for cryptosporidiosis infection.

Cryptosporidiosis and associated variables: The mean age of infected children $(n=13)$ was $2.9 \pm 1.4$. Cryptosporidiosis was more prevalent among males, inhibiting rural areas, using tape water $(61.5 \%$, $69.2 \% \& 69.2 \%$, respectively). Infection was more common among children with preschool age $(46.2 \%)$ followed by toddlers $(38.5 \%)$ and finally infants $(15.4 \%)$. Age groups were significantly associated with infection $(\mathrm{P}=\leq 0.05)$. Source of water and presence of undigested food particles on microscopy were risks for infections $(P$ value $\leq 0.05)$. The diarrhea followed by abdominal pain and pyrexia were presented among infected children $(76.9 \%, 30.8 \%$ \& $23.1 \%$, respectively). About $76.9 \%$ of the Cryptosporidium infected children harbo- 
ured another parasite or commensal on their stool. Stool analysis of infected samples showed undigested food and fat particles $(69.2 \% \& 46.2 \%$, respectively). Only presence of undigested food in stool was predictive for infections $(P=\leq 0.05)$.

Details were given in tables $(1,2 \& 3)$ and figure (1)

Table 1: Microscopy, ELISA and nPCR

\begin{tabular}{|c|c|c|c|c|c|c|c|}
\hline & \multicolumn{3}{|c|}{ Microscopy } & \multicolumn{3}{|c|}{ ELISA } \\
\hline & & $+\mathrm{ve}$ & -ve & Total & $+\mathrm{ve}$ & -ve & Total \\
\hline \multirow{3}{*}{$n$ PCR $(n=13)$} & Positive & $\begin{array}{c}7 \\
(53.8 \%)\end{array}$ & $\begin{array}{c}6 \\
(46.2 \%)\end{array}$ & $\begin{array}{c}13 \\
(6.8 \%)\end{array}$ & $\begin{array}{c}10 \\
(76.9 \%)\end{array}$ & $\begin{array}{c}3 \\
(23.1 \%)\end{array}$ & $\begin{array}{c}13 \\
(6.8 \%)\end{array}$ \\
\hline & Negative & $\begin{array}{c}0 \\
(0 \%)\end{array}$ & $\begin{array}{c}176 \\
(100 \%)\end{array}$ & $\begin{array}{c}176 \\
(93.1 \%)\end{array}$ & $\begin{array}{c}5 \\
(2.8 \%)\end{array}$ & $\begin{array}{c}171 \\
(97.2 \%)\end{array}$ & $\begin{array}{c}176 \\
(93.1 \%)\end{array}$ \\
\hline & Total & $\begin{array}{c}7 \\
(3.7 \%)\end{array}$ & $\begin{array}{c}182 \\
(96.3 \%)\end{array}$ & $\begin{array}{c}189 \\
(100 \%)\end{array}$ & $\begin{array}{c}15 \\
(7.9 \%)\end{array}$ & $\begin{array}{c}174 \\
(92 \%)\end{array}$ & $\begin{array}{c}189 \\
(100 \%)\end{array}$ \\
\hline
\end{tabular}

Table 2: Diagnostic validity of stained microscopy and Ag detection by ELISA

\begin{tabular}{|c|l|l|l|l|l|}
\hline Method & Sensitivity & Specificity & PPV & NPV & Kappa* \\
\hline Microscopy & $53.8 \%$ & $100 \%$ & $100 \%$ & $96.7 \%$ & 0.610 \\
\hline ELISA & $77 \%$ & $97.1 \%$ & $66.6 \%$ & $98.2 \%$ & 0.624 \\
\hline
\end{tabular}

*Kappa agreement interpretation: $<0=$ poor, $0.01-0.20=$ slight, $0.21-0.40=$ fair, $0.41-0.60=$ moderate, $0.61-0.80=$ substantial, and $0.81-1.0=$ almost perfect

Table 3: Risk factors for patients with positive $\mathrm{n}$ PCR for cryptosporidiosis

\begin{tabular}{|c|c|c|c|c|c|c|c|c|}
\hline \multicolumn{3}{|c|}{ Variables } & $\begin{array}{l}+\mathrm{nPCR} \\
\mathrm{n}=13(\%)\end{array}$ & $\begin{array}{l}\text {-ve nPCR } \\
n=176(\%)\end{array}$ & $\begin{array}{c}\text { Total } \\
\mathrm{n}=189(\%)\end{array}$ & $\begin{array}{c}P \\
\text { value }\end{array}$ & $\begin{array}{c}\text { 95\% C.I. } \\
\text { (lower/upper) }\end{array}$ & OR \\
\hline \multirow[t]{2}{*}{$\mathrm{se}$} & \multirow{2}{*}{\multicolumn{2}{|c|}{$\frac{\text { Male }}{\text { Female }}$}} & $8(61.5)$ & $80(45.4)$ & $88(46.5)$ & \multirow[t]{2}{*}{0.2} & \multirow[t]{2}{*}{$0.604 / 6.101$} & \multirow[t]{2}{*}{1.920} \\
\hline & & & $5(38.5)$ & $96(54.5)$ & 101(53.4) & & & \\
\hline \multicolumn{3}{|c|}{ Age years } & $2.9 \pm 1.4$ & $3.2 \pm 2.7$ & $3.1 \pm 1.9$ & 0.07 & & \\
\hline \multirow{3}{*}{\multicolumn{3}{|c|}{$\begin{array}{l}\text { 1. Infants }(>1-2) \\
\text { 2. Toddlers }(1-3) \bullet \\
\text { 3. Preschool }(3-5) \bullet\end{array}$}} & $2(15.4)$ & $26(14.7)$ & $28(14.8)$ & \multirow{3}{*}{$0.02 *$} & & \\
\hline & & & $5(38.5)$ & $76(43.1)$ & $81(42.8)$ & & & \\
\hline & & & $6(46.2)$ & $74(42)$ & $80(42.3)$ & & & \\
\hline \multirow{2}{*}{\multicolumn{2}{|c|}{ Residence }} & Rural & $9(69.2)$ & $135(76.7)$ & $144(76.2)$ & \multirow[t]{2}{*}{0.3} & \multirow[t]{2}{*}{$0.428 / 4.999$} & \multirow[t]{2}{*}{1.463} \\
\hline & & urban & $4(30.8)$ & $41(23.2)$ & $45(23.8)$ & & & \\
\hline \multirow{2}{*}{\multicolumn{2}{|c|}{ Source of water }} & Tape & $9(69.2)$ & $155(82)$ & $164(86.7)$ & \multirow[t]{2}{*}{$0.01 *$} & \multirow[t]{2}{*}{$0.004 / 1.165$} & \multirow[t]{2}{*}{0.069} \\
\hline & & Filtered & $4(30.8)$ & $21(11.9)$ & $25(13.2)$ & & & \\
\hline \multirow{6}{*}{ 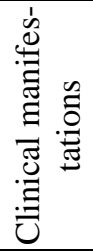 } & \multirow[t]{2}{*}{ Diarrhea } & Yes & $10(76.9)$ & $103(58.5)$ & 113(59.8) & & \multirow[t]{2}{*}{$0.025 / 1.940$} & \multirow[t]{2}{*}{0.150} \\
\hline & & No & $3(23.1)$ & $73(41.5)$ & $76(40.2)$ & & & \\
\hline & \multirow{2}{*}{$\begin{array}{l}\text { Abdominal } \\
\text { pain }\end{array}$} & Yes & $4(30.8)$ & $64(36.4)$ & $68(35.9)$ & \multirow[t]{2}{*}{0.3} & \multirow[t]{2}{*}{$0.428 / 4.999$} & \multirow[t]{2}{*}{0.179} \\
\hline & & No & $9(69.2)$ & $112(63.6)$ & $121(64)$ & & & \\
\hline & \multirow[t]{2}{*}{ Fever } & Yes & $3(23.1)$ & $25(14.2)$ & $28(14.8)$ & \multirow[t]{2}{*}{0.5} & \multirow[t]{2}{*}{$0.442 / 4.515$} & \multirow[t]{2}{*}{1.412} \\
\hline & & No & $10(76.9)$ & $151(85.8)$ & $165(85.2)$ & & & \\
\hline \multirow{10}{*}{ 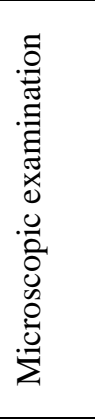 } & \multirow{2}{*}{$\begin{array}{l}\text { Polyparasit- } \\
\text { ism }\end{array}$} & Yes & $10(76.9)$ & $103(58.5)$ & $113(59.8)$ & 0.1 & $0.469 / 6.323$ & 1.790 \\
\hline & & No & $3(23.1)$ & $73(41.5)$ & $76(40.2)$ & & & \\
\hline & Undigested & yes & $9(69.2)$ & $89(50.6)$ & $98(51.8)$ & $0.02 *$ & $0.521 / 6.154$ & 1.058 \\
\hline & food & no & $4(30.8)$ & $87(49.4)$ & $91(48.1)$ & & & \\
\hline & Fat particles & Yes & $6(46.2)$ & $49(27.8)$ & $55(29.1)$ & 0.3 & $0.410 / 6.129$ & 1.586 \\
\hline & & No & $7(53.8)$ & $127(72.2)$ & $134(75.6)$ & & & \\
\hline & RBCs & Yes & $4(30.8)$ & $33(18.7)$ & $37(19.6)$ & 0.19 & $0.588 / 4.589$ & 1.018 \\
\hline & & No & $9(69.2)$ & $143(81.3)$ & $152(80.4)$ & & & \\
\hline & Pus cells & Yes & $5(38.5)$ & $38(21.6)$ & $43(22.7)$ & 0.17 & $0.293 / 1.297$ & 1.418 \\
\hline & & No & $8(61.5)$ & $138(78.4)$ & 146(77.2) & & & \\
\hline
\end{tabular}

-According to CDC, 2018, * significant $P$ value $(\leq 0.05)$.

\section{Discussion}

The present study revealed cryptosporidiosis infection among $6.8 \%$ of children. The preschool children were the most affected $(46.2 \%)$ followed by toddlers and infants (38.5\% \& $15.4 \%$, respectively) with the age 
group significant association $(\mathrm{P}=\leq 0.05)$. The children with preschool age used to play with pet animals, attend day care centers where wide range of risk factors for acquiring cryptosporidiosis are available at these communities at Egypt. Children are exposed to poor quality of water supply and infected children at nursery centers. One can't neglect the contaminated food when large number of children is on the responsibility of one person during feeding time. In addition to the poor personal hygiene for washing hands of children or their nanny during feeding and lake of following preventive tools by children to avoid infections at this age. These conditions express the high rate of infection at preschool children (Bouzid et al, 2018; Ghieth et al, 2018). The toddlers were the second affected age group (38.5\%); child at this age underwent a near social pattern to preschool age for attending day care center communities. In addition, toddlers are just start to be independent; they used to discover the world through sucking and tasting things, their toys and hands, an attitude making them vulnerable for infection.

In the present study, infants were the least affected group; two infants $(15.4 \%)$ were Cryptosporidium positive by nPCR and were on bottle feeding, their mothers used to prepare milk formula by adding tape water to the milk powder. Also, they were complaining of diarrhoea.

During the first year, the child was more protected from Cryptosporidium especially those on exclusive breast feeding (Bouzid et $a l, 2018$ ). The fact that, breast milk shared nonspecifically by providing lactoferrrin and specifically by IgA, that target the wall of Cryptosporidium oocyst improving protection against infection specially at endemic regions (Korpe et al, 2013). During the early 6 months; mothers milk protect infant by specific IgA against cryptosporidiosis, while during the weaning period the child is more exposed to acquire infection (Steinberg et al, 2004).

In Egypt, Naguib et al. (2018) found that the frequent infections were at the ages of $\leq$ 3 \& 4 years; El Matrawy et al. (2017) and Taha et al. (2018) reported the age range $\leq 3$ to 9 with higher positivity for cryptosporidiosis. Besides, below the age of two; Cryptosporidium DNA product wasn't detected by nPCR (Taha et al, 2018). Similar results were recorded by Al-Shamiri et al. (2010) in Yemen children.

In contrast, others reported high infection rates below the ages of one (Bushen et al, 2007; Murugesan et al, 2017; Saha et al, 2019), and two (Hossain et al, 2019).

Dis-similarity between studies were in view of differences in the studied population, immunity, nutrition, time of weaning, either exclusive or non-breast feeding. Some mothers' traditional behaviors during the early childhood; forced the child to eat by his mother with bare hand increasing the chance for acquiring infection. Also the type of diet introduced to children with high carbohydrates and/or sugar low protein content, a diet pattern negatively affecting immunity and increasing inflammatory response.

Molecular diagnosis of cryptosporidiosis using nPCR was crucial (Ghieth et al, 2018), helped to detect infection among false negative cases by microscopy and ELISA. Microscopy betted on ELISA gave maximum specificity \& PPV (100\% for each), but some positive cases were missed due to low sensitivity $(53.8 \%)$. The ELISA sensitivity (77\%) was higher than stool. But, false positive cases and missed infections were restrictions (specificity 97.1\%, \& PPV 66.6\%).

The false negative results by ELISA may be by virtue of the used the monoclonal antibodies within the kits that tagged variable surface epitopes sets which may be not bind to all Cryptosporidium species. The persistence of antigenemia after clearance of infection or cross reactivity with other antigens boosts false positivity of ELISA (Ghoshal et $a l, 2018)$. In such a way, using nPCR alongside microscopy or ELISA is decisive for the diagnosis Cryptosporidium infection.

In the present study, infected children used 
tape water (69.2\%) and filtered water (30.8), source of water supply was a risk for infection ( $P$ value $\leq 0.05)$. Cryptosporidium oocyte was missed by chlorination; beside tape water in urban are stored over building tanks which can maintain infection if water is contaminated. Cryptosporidium is a small size 4-6um water transmitted infection that escapes filtration devices, resists chemicals and being insistent in the environment (WHO 2006). In rural areas contamination of water surfaces, wells and stagnant water that used in domestic life are sources of oocyst. In addition to entertainment activities by children at early childhood age, and giving tape water to infants for drinking and preparing food could be sources of infection (Antonios et al, 2001).

In the present study, diarrhea was the most presented complains (76.9\%), followed by abdominal pain and pyrexia $(30.8 \%, 23.1 \%$, respectively). Stool analysis of $76.9 \%$ of infected children was positive for one parasite or commensals, distributed as follow Giardia intestinalis, Entamoeba complex, Entamoeba coli, Blastocyst hominis (40\%, 30\%, 20\%, \& 10\%, respectively). Since Cryptosporidium is acquired orally, it wasn't a surprise finding polyparasitism among children as they share the same route of infection (Ghieth, 2016; Moyo et al, 2017). This explained the variation of the clinical complains among the present studied populations. Stool analysis of infected samples showed undigested food and fat particles $(69.2 \%, 46.2 \%$, respectively), which was predictive for cryptosporidiosis $(\mathrm{P}=0.02)$.

\section{Conclusion}

Cryptosporidium is paediatric infection common among the preschool, toddlers and infants with the gastrointestinal manifestations especially diarrhea.

The source of water is suspected as risk for infection. Rate of filtered water transmitted cryptosporidiosis is lower than tape water.

The presence of the undigested food particles in stool predicated the cryptosporidiosis infection.
Consequently, the nPCR proved to be a good diagnostic tool to monitor Cryptosporidium infection.

\section{Acknowledgment}

The authors are appreciating to the Scientific Research Developing Unit, Beni-Suef University for funding the Research to Dr. Hala M. El-Askary.

Thanks are also to the Diagnostic \& Research Unit of Parasitic Diseases, Medical Parasitology Department, Faculty of Medicine, Beni-Suef University for proceeding and samples storage, as well as the Pediatrics Outpatients Clinic, Faculty of Medicine, BeniSuef University, for collection of samples.

\section{References}

Abdel Gawad, SS, Ismail, M, Imam, N, Eassa, A, Abu-Sarea, EY, 2018: Detection of Cryptosporidium spp. in diarrheic immunocompetent patients in Beni-Suef, Egypt: Insight into epidemiology and diagnosis. Korean J. Parasitol. 56, 2: 113-9.

Al-Shamiri, A, Al-Zubairy, A, Al-Mamari, R, 2010: The prevalence of Cryptosporidium spp. in children, Taiz District, Yemen. Iranian J. Parasitol. 5, 2:26-32.

Antonios, SN, Salem, SA, Khalifa, EA, 2001: Water pollution is a risk factor for Cryptosporidium infection in Gharbia Governorate. J. Egypt. Soc. Parasitol. 31, 3:963-4

Bouzid, M, Hunter, PR, Chalmers, RM, Tyler, KM, 2013: Cryptosporidium pathogenicity and virulence. Clin Microbiol Rev. 26, 1:115-34. Bouzid, M, Kintz, E, Hunter, PR, 2018: Risk factors for Cryptosporidium infection in low and middle income countries: A systematic review and meta-analysis. PLoS Negl. Trop. Dis., 12: 6, e0006553. doi:10.1371/ journal.pntd.0006553

Bushen, OY, Kohli, A, Pinkerton, RC, Dupnik, K, Newman, RD, et al, 2007: Heavy cryptosporidial infections in children in the Northeast Brazil: Comparison of Cryptosporidium hominis and Cryptosporidium parvum. Trans. R. Soc. Trop. Med. Hyg, 101:378-84.

CDC, 2018: Information for Parents of Infants \& Toddlers (Approximate Ages 0-3), Preschoolers (3-5 years of age).

El-Matrawy, OM, Hassan, MA, Morsy, SM, Rubio, JM, El-Badry, AA, 2017: Molecular diagnosis of Cryptosporidium spp. versus micro- 
scopy in diarrheic patients in Cairo. J. Egypt Soc. Parasitol. 47, 2:303-8.

Fathy, MM, Abdelrazek, NM, Hassan, FA, El-Badry, AA, 2014: Molecular copro-prevalence of Cryptosporidium in Egyptian children and evaluation of three diagnostic methods. Indian Pediatr. 51, 9:727-9.

Ghieth, MA, 2016: Coproscopic parasitism among Beni-Suef community, Egypt: Prevalence and risk factors. Egypt. J. Med. Sci. 37, 2:556-7. Ghieth, MA, El-Badry AA, Abu-Sarea, EY, Kotb, MA, 2018: Intestinal parasitosis and pediatric hepatic disease: coproscopy and immunomolecular assays. J. Egypt. Soc. Parasitol. 48, 2: 475-80

Ghoshal, U, Jain, V, Dey A, Ranjan, P, 2018: Evaluation of enzyme linked immunosorbent assay for stool antigen detection for the diagnosis of cryptosporidiosis among HIV negative immunocompromised patients in a tertiary care hospital of Northern India. J. Infect. Publ. Hlth. 11: 115-9.

Helmy, YA, Krücken, J, Nöckler, K, et al, 2014: Comparison between 2 commercially available serological tests and polymerase chain reaction in diagnosis of Cryptosporidium in animals \& diarrheic children. Parasitol. Res. 113: 211.https://doi.org/10.1007/s00436-013-3645

Hossain, MJ, Saha, D, Antonio, M, Nasrin, D, Blackwelder, WC, et al, 2019: Cryptosporidium infection in rural Gambian children: Epidemiology and risk factors. PLOS Negl. Trop. Dis. 13, 7: e0007607. https://doi.org/10.1371/journal. pntd.0007607

Khalil, IA, Troeger, C, Rao, PC, et al, 2018: Morbidity, mortality and long-term consequences associated with diarrhea from Cryptosporidi$u m$ infection in children younger than 5 years: A meta-analyses study. Lancet Glob. Hlth. 6: e75868.

Korpe, PS, Liu, Y, Siddique, A, Kabir, M, Ralston, K, Ma, JZ, et al, 2013: Breast milk parasite-specific antibodies and protection from amebiasis and cryptosporidiosis in Bangladeshi infants: A prospective cohort study. Clinical infectious diseases: an official publication of the Infectious Diseases Society of America. 56, 7: 988-92.

Mor, SM, Tzipori, S, 2008: Cryptosporidiosis in children in Sub-Saharan Africa: A lingering challenge. Clin. Infect. Dis. 47, 7:915-21.

Moyo, SJ, Kommedal, Ø, Blomberg, B, et al,
2017: Comprehensive analysis of prevalence, epidemiologic characteristics, and clinical characteristics of monoinfection and coinfection in diarrheal diseases in children in Tanzania. Am. J. Epidemiol. 186:1074-83

Murugesan, M, Ganesan, SK, Ai.jampur, SS, 2017: Cryptosporidiosis in children in the Indian subcontinent. Trop. Parasitol. 7, 1:18-28.

Naguib, D, El-Gohary, AH, Roellig, D, Mohamed, A, Arafat, N, et al, 2018: Molecular characterization of Cryptosporidium spp. \& Giardia duodenalis in children in Egypt. Parasites Vectors 11, 1:403. doi:10.1186/s13071-018-2981-7

Nath, J, Hussain, G, Singha, B, Paul, J, Ghosh, SK, 2015: Burden of major diarrhea genic protozoan parasitic co-infection among amoebic dysentery cases from North East India: A case report. Parasitology 142:1318-25

Pedraza-Diaz, S, Amar, C, McLauchlin, J, 2000: The identification and characterization of an unusual genotype of Cryptosporidium from human faeces as Cryptosporidium meleagridis. FEMS Microbiol. Lett. 189, 2:189-94

Saha, R, Saxena, B, Jamir, ST, Shekhar, S, 2019: Prevalence of cryptosporidiosis in symptomatic immunocompetent children and comparative evaluation of its diagnosis by Ziehl-Neelsen staining and antigen detection techniques. Trop. Parasitol. 9, 1:18-22.

Spano, F, Putignani, L, McLauchlin, J, Casemore, DP, Crisanti, A, 1997: PCR-RFLP analysis of the Cryptosporidium oocyst wall protein (COWP) gene discriminates between $C$. wrairi and $C$. parvum, and between $C$. parvum isolates of human and animal origin. FEMS Microbiol. Let. 150: 209-17.

Steinberg, EB, Mendoza, CE, Glass, R, Arana, B, Lopez, MB, et al, 2004: Prevalence of infection with waterborne pathogens: A sero-epidemiologic study in children 6-36 months old in San Juan Sacatepequez, Guatemala. Am. J. Trop. Med. Hyg. 70, 1:83-8.

Taha, SA, Abd Al Aal, Z, Saleh, NS, El-Badry, AA, 2018: Cryptosporidium hominis predominance among symptomatic Egyptian children. J. Egypt. Soc. Parasitol. 48, 3:611-7

White, AC, Jaganath, D et al, 2015: A review of the global burden, novel diagnostics, therapeutics, and vaccine targets for Cryptosporidium. Lancet Infect Dis. 15: 85-94.

WHO 2006: WHO Guidelines for Drinking Water Quality, 02 January 2006 


\section{Explanation of figure}

Fig.1: A- Agarose gel electrophoresis, L: DNA marker (100-bp); lane 1: positive control; lane 2: negative control; lanes 3-6: nPCR product at 553 bp targeting COWP gene of Cryptosporidium. B- Cryptosporidium oocyst stained with MZN stain, x100 oil immersion.

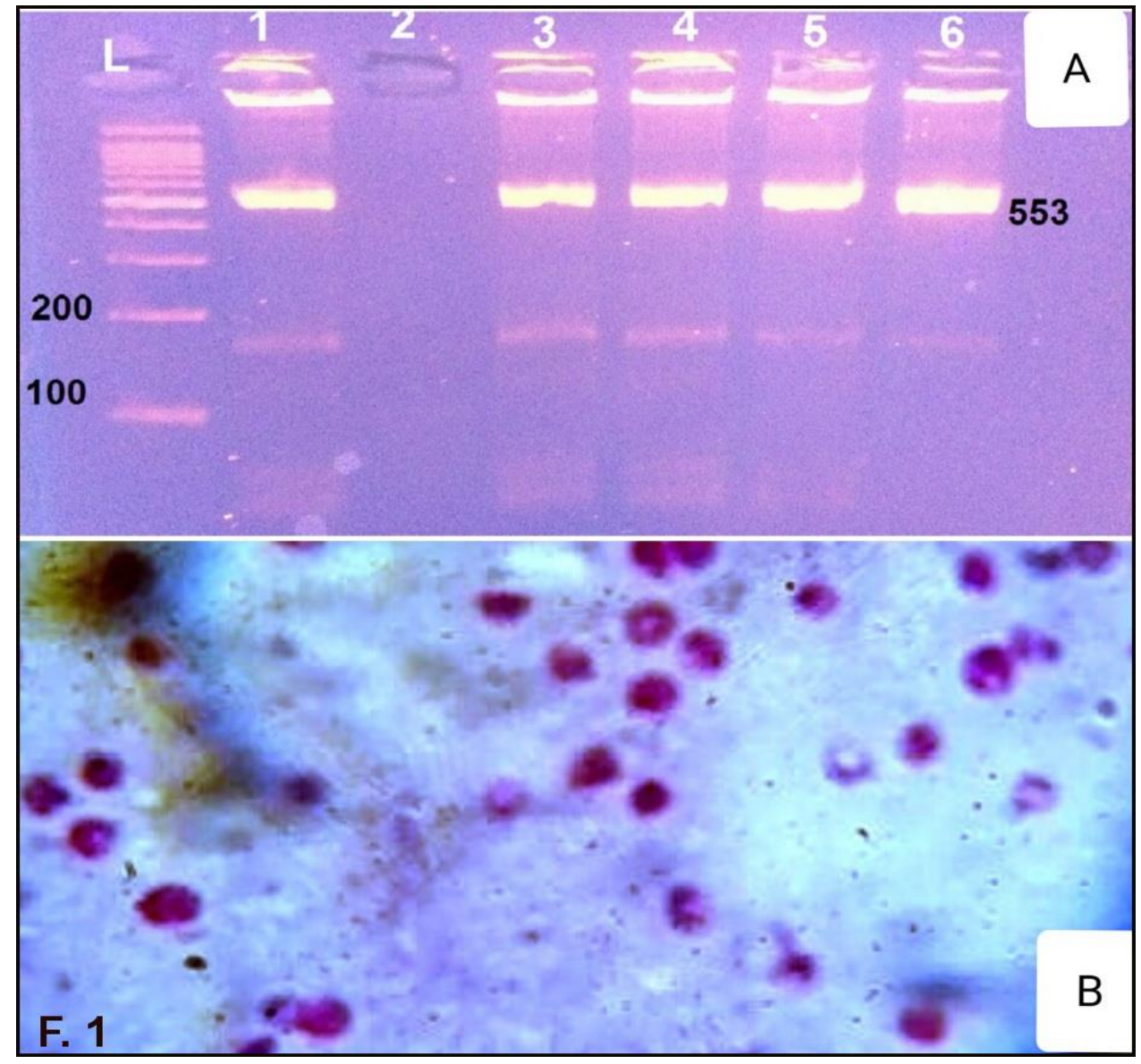

